\title{
The Effect of Changeable Urban Albedo on Solar Radiation Incident on Vertical Facade
}

\author{
Dominika Knera ${ }^{1}$, Dariusz Heim ${ }^{1}$ \\ ${ }^{1}$ Department of Environmental Engineering, Lodz University of Technology, Poland
}

\begin{abstract}
In the energy building performance simulations, the reflected solar radiation is conventionally calculated using constant albedo value. However, considering building facades located in urban environment more precise modelling of reflected solar radiation is necessary. In presented paper, the new method of determination of reflected solar radiation in urban area using HDR image technique is described. Based on the obtained results new model of reflected solar radiation was established and implemented into ESP-r. Finally, the validation of proposed model was conducted taking into account calculated and measured value of solar radiation incident on western oriented façade.
\end{abstract}

\section{Introduction}

Detailed determination of the total solar radiation reaching vertical surface is very important for evaluation of energy performance of passive and active solar systems located at building facades. Total solar radiation incident on tilted surface consist of three components: direct solar radiation from sun disc, diffuse solar radiation from sky dome and reflected solar radiation from ground. Transitions models of solar radiation incident on tilted surface available in the literature have been changing from simple model assuming isotropic character of sky diffused radiation (Liu and Jordan, 1960) to complex one with consideration of the anisotropic character of the sky radiation (Perez et al., 1990). However, in energy performance simulations reflected solar radiation is usually modelled in the same way using simple Liu and Jordan (1963) model with constant monthly value of ground reflectivity. Nevertheless according to the Ineichen et all. (1987) the correct estimation of reflected radiation is essential for good evaluation of solar radiation incident on tilted surface. Many more advanced models of ground reflectivity have been developed by different authors. Nkemdirim proposed model (1972) of ground reflectivity dependent on the sun position. Gueymard's model (1987) proposed a more complex approach to albedo: two individual ground reflectance coefficients were considered for direct and diffuse radiation (Gueymard, 1987). Moreover, the characteristics of surrounding environment, like occurrence of snow cover, have significant impact on reflected solar radiation. Thevenard and Haddad (2006) proposed detailed model of ground reflectivity as a function of the snow cover occurrence and depth.

The general model of reflected solar radiation used in Perez 1990 model is presented in Equation 1. Reflected solar radiation is function of the total horizontal solar irradiance, ground reflectivity and ground view factor (GVF). The GVF is geometric coefficient defining part of the ground visible from the tilted surface. Formula (1) present general model of reflected solar radiation used in building energy performance simulations.

$$
\begin{gathered}
I_{S, r e f l}=I_{h, \text { tot }} \cdot \gamma_{r e f l} \cdot \mathrm{GVF} \\
G V F=\left(\frac{1-\cos \beta}{2}\right)
\end{gathered}
$$

where:

$I_{S, \text { refl }}-$ total reflected solar irradiance incident on inclined surface $\left[\mathrm{W} / \mathrm{m}^{2}\right]$,

$I_{h, t o t}-$ total horizontal solar irradiance $\left[\mathrm{W} / \mathrm{m}^{2}\right]$,

$\gamma_{\text {refl }}$ - ground reflectivity (albedo) [-],

GVF - ground view factor [-],

$\beta$ - surface tilt angle from horizon $\left[{ }^{\circ}\right]$.

Considering vertical surface, the GVF is equal 0.5. However, in urban area the GVF is commonly higher because of surrounding buildings and greenery that obscure partially the sky dome. Yoon et al., (2014) propose photographical method for determination of precise value of sky and ground view factors. Gong et al., (2018) establish individual sky, tree and building view factors (SVF), (TVF), (BVF) of street canyons using Google Street View (GSV) images and a deeplearning algorithm.

In urban area, the determination of reflected solar radiation is a complex issue. Urban scene consists of many different surfaces of building envelopes, ground covering and greenery, characterised by various reflectivity (Figure 1). Moreover, Reflected solar radiation could change throughout day and year because of changes in the surrounding environment characteristics and sun position.

In presented paper was proposed the new method to evaluate reflected solar radiation in urban area using photogrammetric technique (HDR image) and luminous efficacy. Reflected solar radiation for two selected days characterised by sunny and cloudy sky conditions in September was determined using proposed method. Subsequently, based on the obtained results new model of reflected solar radiation was developed and 
implemented into ESP-r software source code. Finally, the validation of proposed model was conducted by comparison of the value of solar radiation incident on western oriented façade obtained from simulation and measurements. The main aim of the study is an analysis of changing reflected solar radiation incident on vertical façade of building located in the urbanized area.

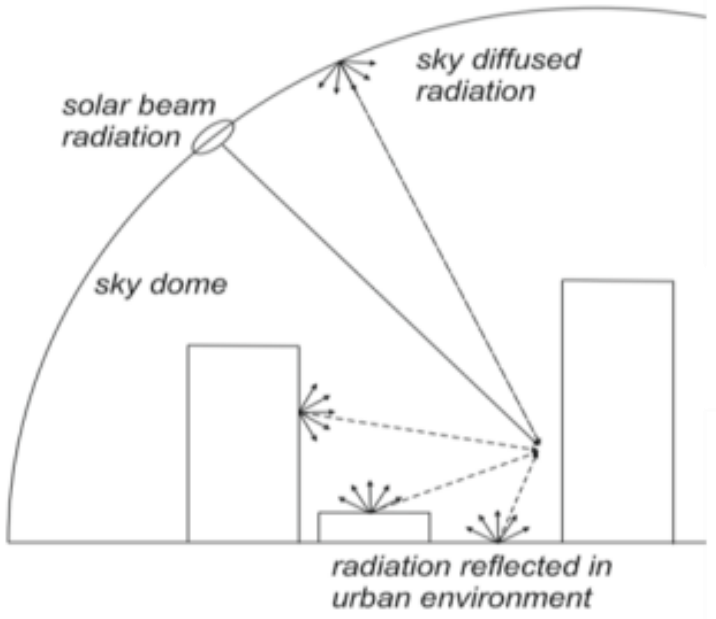

Figure 1: Components of solar radiation incident on the building façade in the urban environment.

\section{Methodology}

Proposed method to determine reflected solar radiation in urban environment is based on the HDR image technique. Luminance levels in the urban area can vary between $50 \mathrm{~cd} / \mathrm{m}^{2}$ on a dark surfaces and on cloudy days to over $10000 \mathrm{~cd} / \mathrm{m}^{2}$ on a bright surfaces on sunny days. The human eye can register a wide range of luminance in their surrounding recording details in dynamic range of up to 10 000:1. While a standard digital camera can capture a significantly lower dynamic range, only about 1 000:1 (Jacobs 2007). However, using high dynamic range (HDR) technique the wide range of luminance can be registered on digital image. HDR imaging technique is already used in luminance analyses, like daylight distribution in a building interiors (Anaokar and Moeck 2006; Inanici 2006). Considering constant development in digital cameras and lenses, the daylight distribution analysis by digital images is promising.

Proposed method of determination of reflected solar radiation in urban environment consists of seven stages as it is presented in algorithm in Figure 2.

In first stage of the proposed method, five low dynamic range (LDR) digital images of the surroundings were made using fixed camera settings - the same aperture and five shutter speeds. The images were taken using the digital camera Nikon D80 equipped with wide-angle lens Sigma Fish-eye. Applying of lens with $180^{\circ}$ viewing angle enables to represent the whole hemisphere of the surrounding environment at a single digital image. According to the HDR image technique described by Jacobs (2007) photometrical corrected HDR image can be obtained by introduction of following corrections: camera response function calibration as well as vignetting and luminance correction.

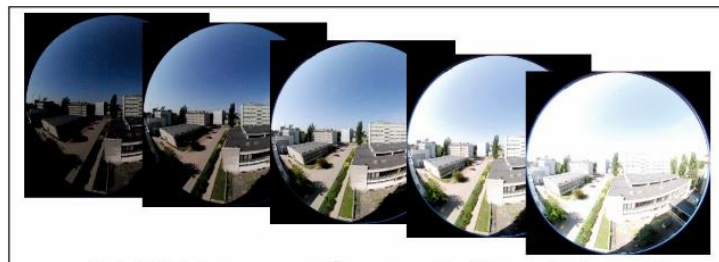

5 LDR images for each time interval
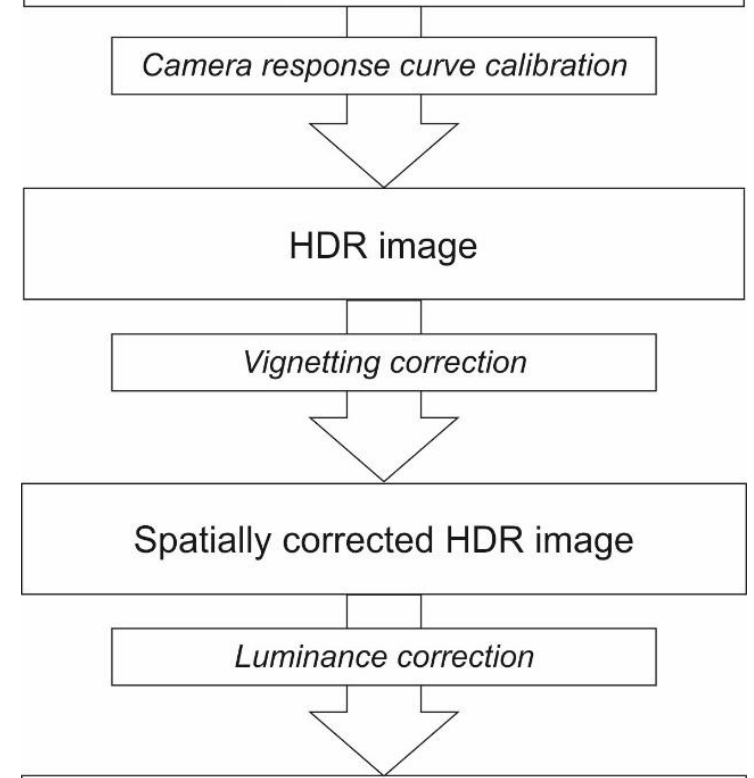

Photometrically corrected HDR image

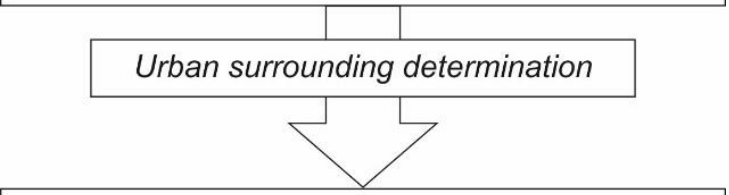

\section{Avaraged luminance of urban surrounding environment}
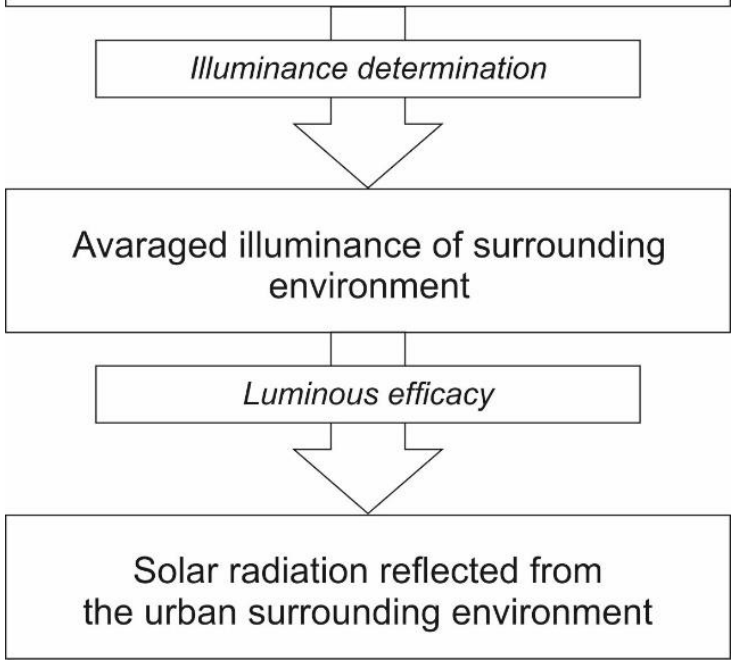

Figure 2: Reflected solar radiation estimation method algorithm. 
The camera response function was determined using additional sequence of digital images of scene including large grey surface with white and black elements. All HDR images were merged using Photosphere software and established camera response curve. Subsequently, study of the vignetting effect characteristic for the fisheye lenses was conducted. Additional analysis was performed to determine the decrease of the luminance at the edges of the image in comparison to the central part of the image. Obtained results showed that vignetting effect for used optical lenses was very low, therefore this correction was neglected. Last stage to obtain photometrical corrected HDR image is the correction of luminance of HDR image using real scene luminance measurements. Simultaneously, the registration of the scenes by camera and measurement of the luminance of selected surfaces in surrounding environment using luminance meter LS-100 were made. Subsequently, the correction coefficients of the luminance of individual surfaces obtained from the HDR image and measurement were calculated. Obtained average correction coefficient was used to correct the luminance of the HDR images.

Next steps of algorithm were devoted to determine the reflected solar radiation from the photometrical corrected HDR image of surrounding environment. Firstly, each HDR image was edited in the program to select part of the image with urban surrounding environment crucial for reflected solar radiation. Then, the average luminance of the selected neighbourhood urban environment was determined. Subsequently, the averaged illuminance at the vertical surface was calculated. In last stage of the method, the reflected solar radiation was determined from the averaged illuminance of surrounding urban environment and luminous efficacy. Luminous efficacy is rate of illuminance to total solar irradiance incident on the same surface. Additional analysis was performed to determine the average luminous efficacy coefficient used in calculation of reflected solar radiation.

Further part of the paper is devoted to establishment of the model of reflected solar radiation based on the obtained results and measured total horizontal solar irradiance. Firstly, correlation analysis of the determined reflected solar radiation with the sun position and total solar radiation was performed. Based on the obtained results and regression analysis the new model of reflected solar radiation was estimated and implemented into building performance simulation software - ESP-r. Subsequently, simulations were performed for two models of reflected solar radiation: basic model with constant value of ground reflectivity and new detailed model of reflected solar radiation proposed by authors. Simulations were performed for selected days in September using measured data of solar radiation as weather data boundary conditions. The validation of the proposed model was conducted in the frame of comparison of total solar irradiance incident on vertical surface measured by pyranometer and obtained from simulation analysis.

\section{Case study}

The study of reflected solar radiation was performed for vertical surface situated on the level of $15 \mathrm{~m}$ above the ground at the western façade of the building located in city centre in Central Europe $\left(51^{\circ} 45^{\prime} \mathrm{N}\right.$ and $\left.19^{\circ} 28^{\prime} \mathrm{E}\right)$.

The position is characterized by moderate climatic conditions and flat terrain in the immediate vicinity. Surrounding environment consists of buildings not higher than $21 \mathrm{~m}$, pavements, roads and greenery. Most of the surrounding buildings have bright vertical surfaces and dark flat roofs. In front of the considered surface is located lower building with dark flat roof and bright walls. Another similar building is located on the left side. The ground surface consists of grey pavements and roads with small part of grass and other greenery. In further distance, there are located bright higher buildings. The view including surrounding environment seen from the position of analysed surface is presented in Figure 3.

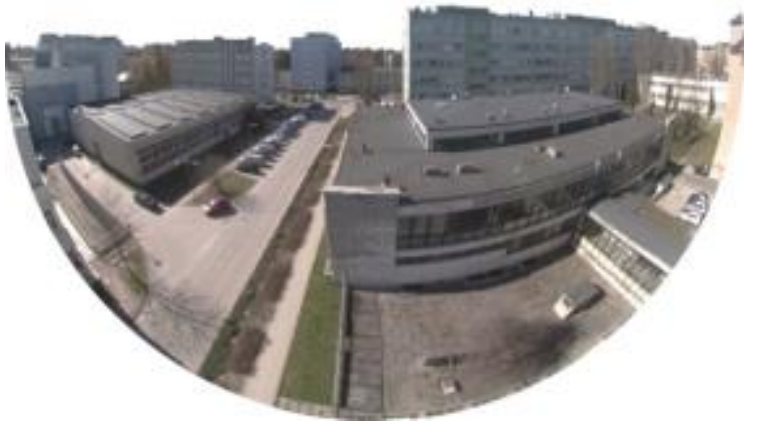

Figure 3: Hemispherical view from the façade.

Additionally, the local weather parameters are monitored by meteorological station located at the roof of the building under consideration. Whole station is equipped with 10 sensors. However, in the presented analysis of reflected solar radiation only following sensors were used:

- pyranometer for measurements of total horizontal solar irradiance $-I_{h, t o t}\left[\mathrm{~W} / \mathrm{m}^{2}\right]$,

- diffuse solar radiation probe with shading ring for measurements of diffused horizontal solar irradiance $-I_{h, \text { diff }}\left[\mathrm{W} / \mathrm{m}^{2}\right]$,

- pyranometer located at western elevation for for measurements of total solar irradiance incident on western façade $-I_{W, \text { tot }}\left[\mathrm{W} / \mathrm{m}^{2}\right]$.

The analysis of the reflected solar radiation was performed for two selected days in September characterised by different sky conditions: sunny (27.09) and cloudy (20.09). The scenes were registered in half an hour interval from the sunrise to sunset. Solar radiation characteristics in selected sunny and cloudy days were presented in the Figure 4. It can be noticed that distribution of solar radiation in cloudy day is fluctuating, which is caused by changing cloud cover during this day. 


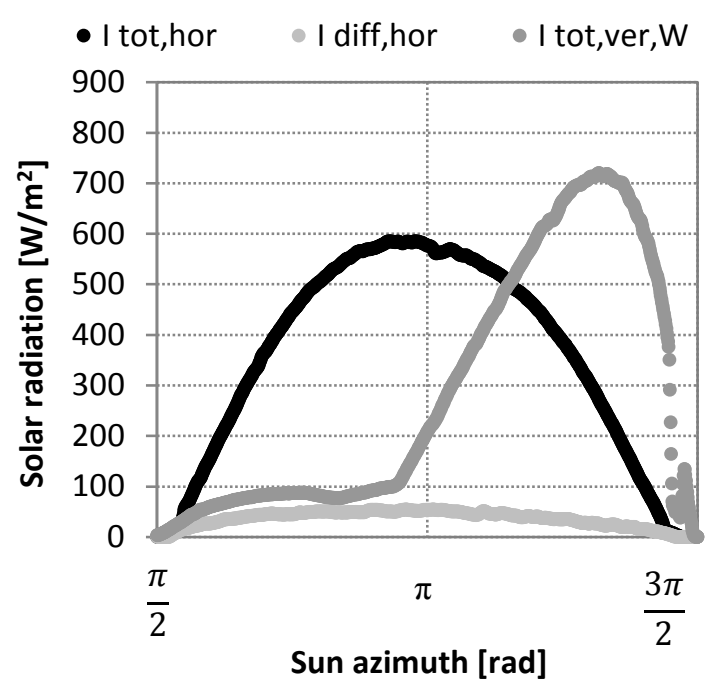

a)
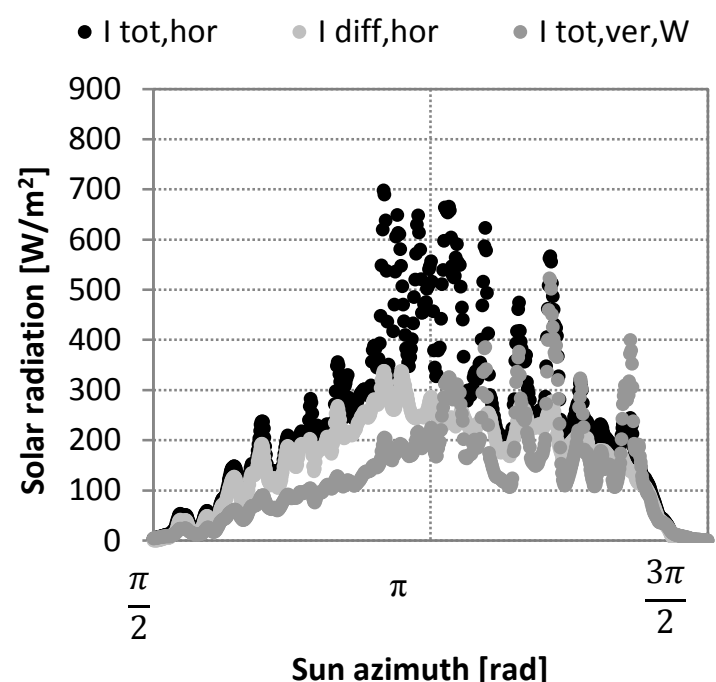

b)

Figure 4: Distribution of solar radiation in selected sunny (a) and cloudy (b) days.

\section{Results}

First part of the results concerns on the obtained averaged luminance for both analysed days presented in the Figure 5. It can be seen that shape of the luminance graph in the sunny and cloudy days differs significantly. Averaged luminance for cloudy day (20.09) increase gradually in first part of the day (sun azimuth $<\pi$ ) and then decrease regularly until sunset (sun azimuth $>\pi$ ). During sunny day the luminance grow fast during first hours until sun azimuth reaches $3 / 4 \pi$ and then reduce fast until noon and gently falls down in second part of day. The maximum value of luminance is noticed during sunny day when solar radiation incident on the vertical surfaces positioned in front of the western facade. Considering the surrounding environment of the analysed surface described peak can be caused by high luminance of the bright green building located in opposite. In second part of the day the level of the determined luminance is similar for both analysed days with sunny and cloudy sky conditions.

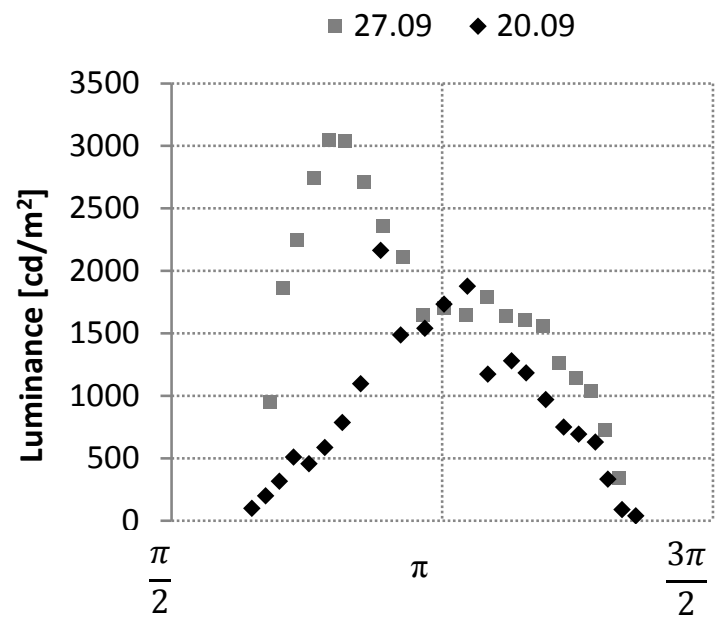

Sun azimuth [rad]

Figure 5: Averaged luminance determined for selected days.

Subsequently in Figure 6 are presented reflected solar radiation graphs for both analysed days. It can be noticed that shape of both graphs is similar to previously described luminance distribution. The maximum value for sunny day is almost $80 \mathrm{~W} / \mathrm{m}^{2}$ while for cloudy day only $40 \mathrm{~W} / \mathrm{m}^{2}$. Moreover, it can be seen that for sunny conditions the reflected solar radiation changing significantly during the day. Considering distribution of total horizontal solar radiation presented in Figure 4 in this day it can be concluded that reflected solar radiation incident on the vertical surface is more complex and cannot be described only by simple dependency from total horizontal solar radiation. Therefore, more detail analysis was performed.

$=27.09 \bullet 20.09$

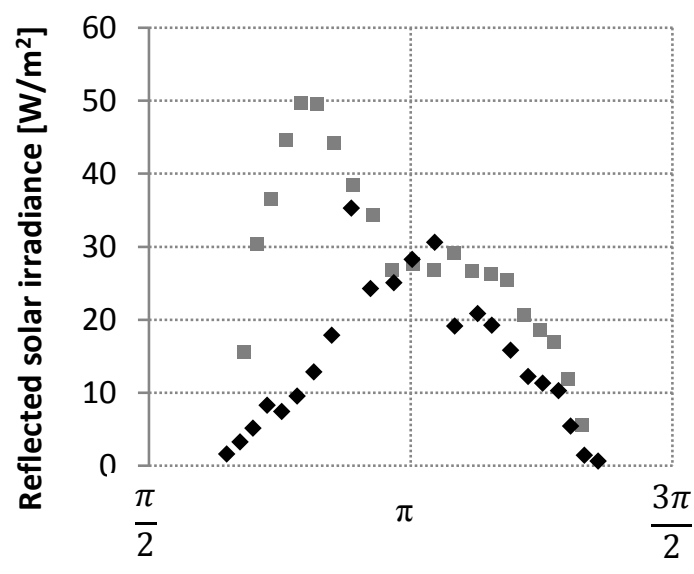

Sun azimuth [rad]

Figure 6: Determined reflected solar radiation in urban environment. 


\section{Model of reflected solar radiation}

In the next part of the paper, the analysis of dependency between determined reflected solar radiation and known parameters like total horizontal solar irradiance $\left(I_{h, t o t}\right)$, sun azimuth (SAZI) and sun altitude (SALT) was performed. These relationships are presented in the Figures 6 and 7. It can be observed that simple linear dependence occurs between reflected solar radiation and total horizontal solar radiation as well as sun altitude for cloudy day. Correlation coefficients presented in Table 1 confirm high linear relationship between these variables in cloudy day. On the other hand, distribution of reflected solar radiation in sunny day is more complex and varies in morning and afternoon hours. Therefore, correlation analysis was preformed individually for first $(S A L T<\pi)$ and second $(S A L T>\pi)$ part of sunny day. Distribution of reflected solar radiation in morning hours resembles the shape of parabola. While in afternoon hours distribution of reflected solar radiation is more linear. The correlation coefficients presented in Table 1 confirm described differences.

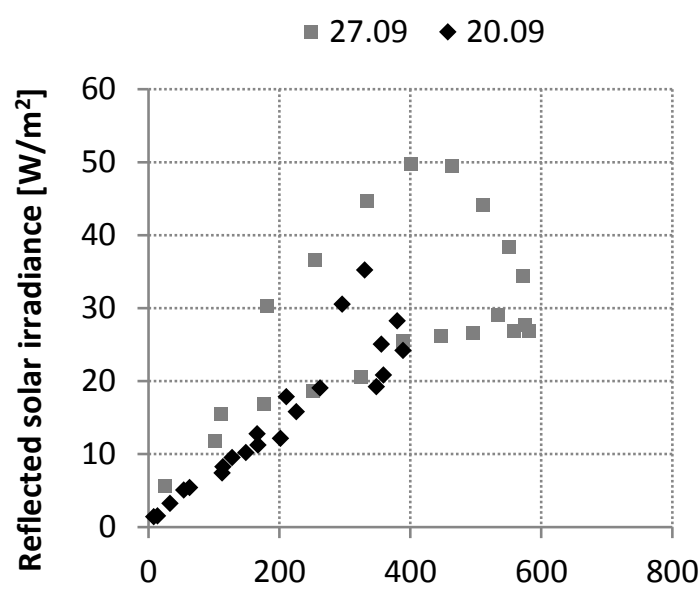

Total horizontal irradiance $\left[\mathrm{W} / \mathrm{m}^{2}\right]$

- $27.09 \bullet 20.09$

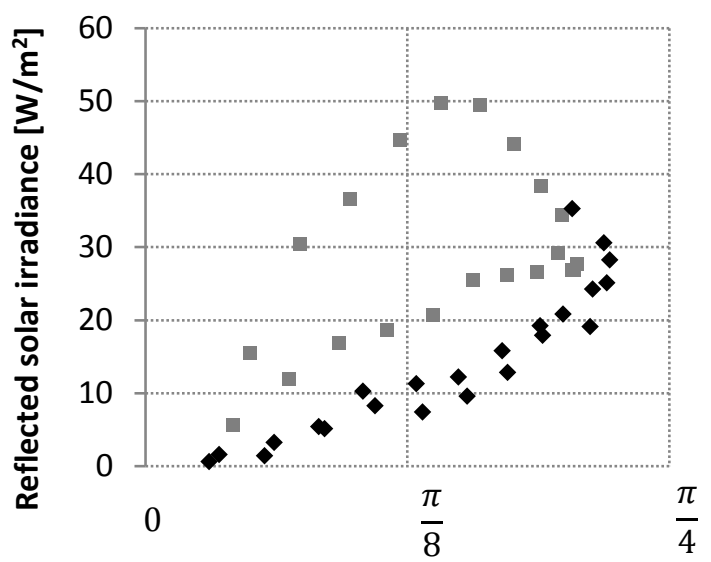

Sun altituae [rad]

Figure 7: Correlation of determined reflected solar radiation with total horizontal solar radiation and sun altitude.
Table 1: Correlation coefficients.

\begin{tabular}{|c|c|c|c|}
\hline \multirow{2}{*}{ Variables } & \multicolumn{3}{|c|}{ Day } \\
\cline { 2 - 4 } & \multirow{2}{*}{$\mathbf{2 0 . 0 9}$} & \multicolumn{2}{|c|}{$\mathbf{2 7 . 0 9}$} \\
\cline { 2 - 4 } & & SALT $<\boldsymbol{\pi}$ & SALT $>\boldsymbol{\pi}$ \\
\hline$I_{h, \text { tot }}\left[\mathrm{W} / \mathrm{m}^{2}\right]$ & 0.93 & 0.41 & 0.96 \\
\hline$S A L T[\mathrm{rad}]$ & 0.92 & 0.38 & 0.97 \\
\hline$S A Z I[\mathrm{rad}]$ & 0.01 & 0.17 & -0.85 \\
\hline
\end{tabular}

Based on the correlation analysis, authors chose two variables with the highest correlation coefficients to use in model of reflected solar radiation: $I_{h, t o t}\left[\mathrm{~W} / \mathrm{m}^{2}\right]$, $S A L T$ [rad]. Taking into consideration different characteristics of reflected solar radiation for sunny and cloudy sky conditions model was divided into two parts. First part of model was estimated for calculation of reflected solar radiation in cloudy sky conditions characterised by rate of diffused horizontal solar irradiance to total horizontal solar irradiance higher than 0.27 . Value of the 0.27 was assumed according to the division of sky types described in (Lam and $\mathrm{Li}, 1996$ ). Second part was devoted to determination of reflected solar radiation for clear sky conditions characterised by coefficient of diffused horizontal solar irradiance to total horizontal solar irradiance less or equal 0.27. First part of model was determined based on the results from cloudy day (20.09). Second part was determined based on the results from sunny day (27.09) individually for first and second part of day.

For both parts of model, the regression analysis was performed individually. For first part the linear multiple regression analysis was performed because of the linear character of reflected solar radiation. The formula for first part of model was presented in Equation 2. The regression statistics were presented in Table 2 and determined coefficients A and B in Table 3.

Subsequently, regression analysis was performed for second part of model. However, the nonlinear distribution of reflected solar radiation was observed in sunny day. Therefore, the polynomial multiple regression analysis was conducted for sunny day with consideration of additional variable: square of the total horizontal solar radiation $\left(\left(I_{h, t o t}\right)^{2}\left[\left(\mathrm{~W} / \mathrm{m}^{2}\right)^{2}\right]\right)$. The formula for first part of model was presented in Equation 3. The regression statistics were presented in Table 2 and determined coefficients $\mathrm{A}, \mathrm{B}$ and $\mathrm{C}$ in Table 3 .

$$
\begin{gathered}
\text { I } \quad I_{u, r e f l}=A \cdot I_{h, t o t}+B \cdot S A L T \\
\text { II } \quad I_{u, r e f l}=A \cdot I_{h, t o t}+B \cdot S A L T+C \cdot\left(I_{h, t o t}\right)^{2}
\end{gathered}
$$

Where

A - coefficient of total horizontal solar radiation [-],

B - coefficient of sun altitude $\left[\mathrm{W} /\left(\mathrm{rad} \cdot \mathrm{m}^{2}\right)\right]$,

C - coefficient of square of total horizontal solar radiation $\left[\mathrm{m}^{2} / \mathrm{W}\right]$,

$I_{h, t o t}-$ total horizontal solar radiation $\left[\mathrm{W} / \mathrm{m}^{2}\right]$,

SALT - sun altitude [rad]. 
Table 2: Regression statistics.

\begin{tabular}{|c|c|c|c|}
\hline \multirow{3}{*}{$\begin{array}{c}\text { Regression } \\
\text { statistics }\end{array}$} & \multicolumn{3}{|c|}{ Sky conditions } \\
\hline & \multirow{2}{*}{$\begin{array}{l}\frac{I_{h, \text { diff }}}{I_{h, \text { tot }}} \\
\leq 0.27\end{array}$} & \multicolumn{2}{|c|}{$\frac{I_{h, \text { diff }}}{I_{h, \text { tot }}}>0.27$} \\
\hline & & SALT $<\pi$ & SALT $>\pi$ \\
\hline $\mathrm{R}^{2}$ & 0.96 & 0.98 & 0.99 \\
\hline $\begin{array}{c}\text { standard } \\
\text { deviation } \\
{\left[\mathrm{W} / \mathrm{m}^{2}\right]}\end{array}$ & 3.77 & 1.49 & 1.11 \\
\hline
\end{tabular}

Table 3: Model coefficients.

\begin{tabular}{|c|c|c|c|}
\hline \multirow{3}{*}{$\begin{array}{c}\text { Model } \\
\text { parameters }\end{array}$} & \multicolumn{3}{|c|}{ Sky conditions } \\
\hline & \multirow{2}{*}{$\begin{array}{l}\frac{I_{h, \text { diff }}}{I_{h, t o t}} \\
\leq 0.27\end{array}$} & \multicolumn{2}{|c|}{$\frac{I_{h, \text { diff }}}{I_{h, \text { tot }}}>0.27$} \\
\hline & & SALT $<\pi$ & SALT $>\pi$ \\
\hline A & 0.0552 & 0.6556 & 0.0292 \\
\hline B & 8.7106 & -332.8463 & 41.4061 \\
\hline $\mathrm{C}$ & - & -0.0004 & -0.00005 \\
\hline
\end{tabular}

General formula of presented model (Equations 2 and 3) reflects changing characteristics of reflected solar radiation in urban environment caused by various sky conditions (sunny and cloudy) as well as sun position (sun azimuth $>\pi$, (sun azimuth $<\pi$ ). This general formula can be used in calculation of reflected solar radiation in average dense urban environment. However, determined coefficients (A, B and C) need to be determined individually for every location.

\section{Validation of proposed model}

Determined model was implemented into opensource software for environment systems performance analysis - ESP-r (Clarke, 2001). New model of reflected solar radiation was introduced in the software source code in subroutine responsible for calculation of solar radiation incident on the inclined surface.

Validation of proposed model was conducted in the frame of comparison of the value of solar radiation incident on western oriented façade obtained from simulation and measurements. Simulation analysis was performed for September with 5 minutes time step. Weather data used for simulation were introduced based on the measured in meteorological station value of the total and diffused solar radiation incident on the horizontal surface.

The direct and sky diffused solar radiation were calculated using standard Perez 1990 model. The reflected solar radiation was determined using authors model and basic model with constant value of ground reflectivity equal 0.2 . Obtained results were compared with real measured value of total solar radiation incident on the western façade. The graph of the total solar radiation incident on analysed vertical surface in selected days is presented in the Figure 8. It can be seen that calculated and measured values of solar radiation are comparable.

Moreover, to compare the calculated and measured solar radiation three statistical indicators were calculated for all analysed days:

- $\quad$ normalized Mean Absolute Error - nMAE [\%],

- normalized Root Mean Square Error - nRMSE [\%],

- coefficient of determination $\mathrm{R}^{2}[-]$.

The obtained averaged values of mentioned factors for selected days were presented in the Table 4.

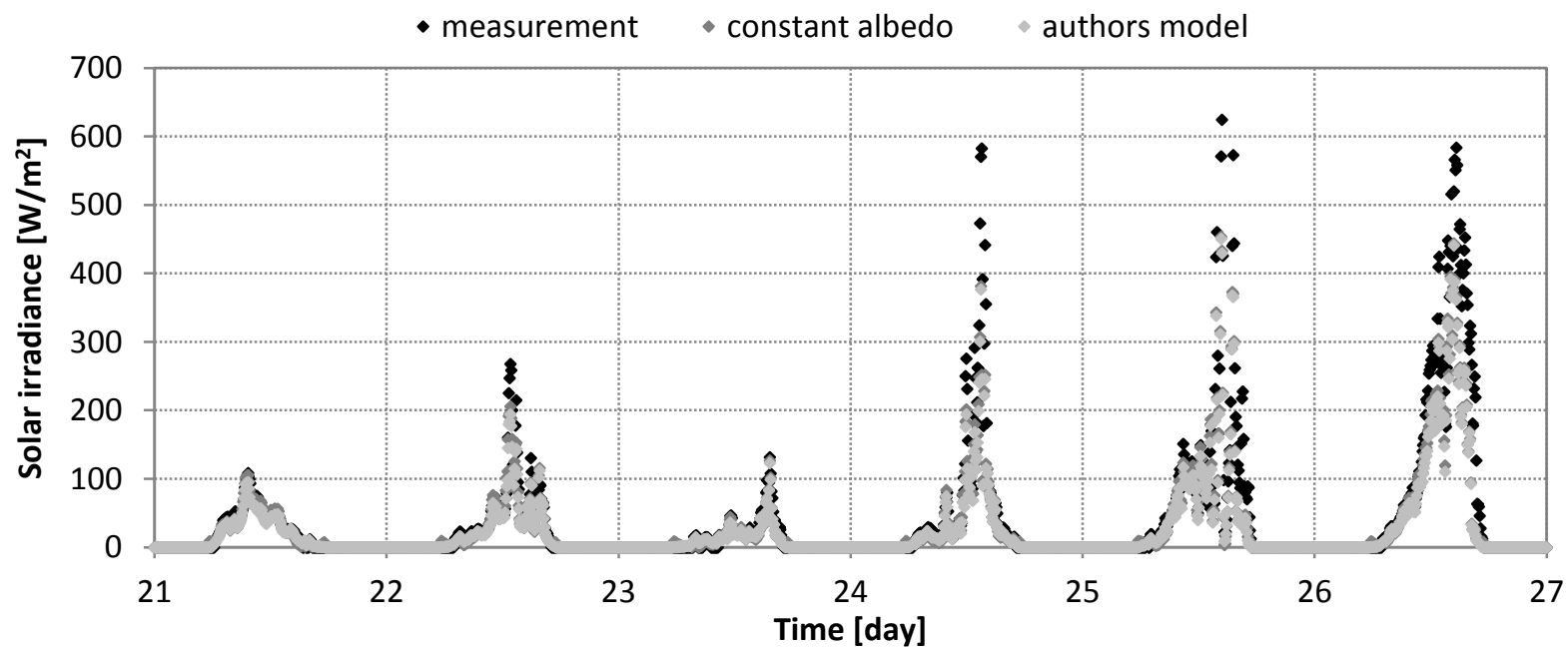

Figure 8:Measured and calculated solar radiation incident on western oriented façade during selected days of September. 


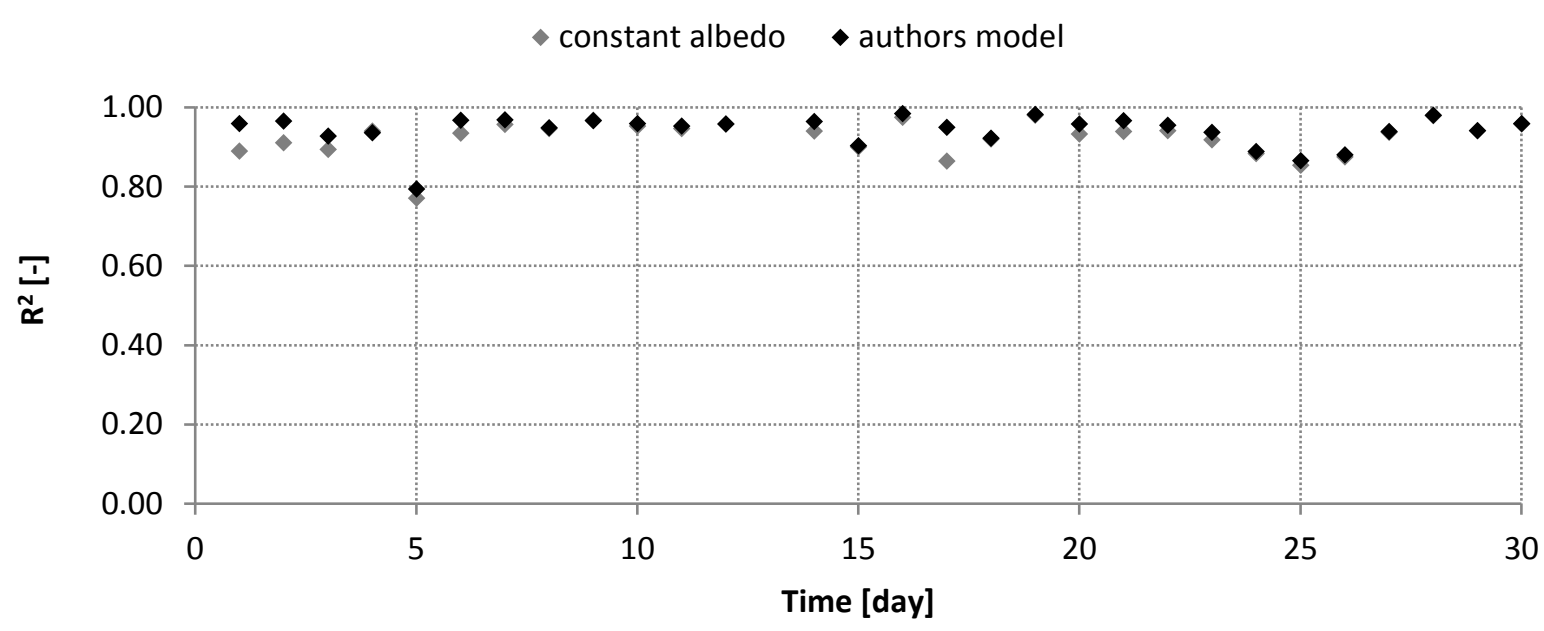

Figure 9:Coefficient of determination $R^{2}[-]$ evaluated for individual days during September.

Table 4: Results from statistical analysis for models with constant albedo (CA) and authors model of reflected solar radiation (AM).

\begin{tabular}{|c|c|c|c|c|c|c|}
\hline \multirow{2}{*}{ Day } & \multicolumn{2}{|c|}{ nMAE [\%] } & \multicolumn{2}{c|}{ nRMSE [\%] } & \multicolumn{2}{c|}{$\mathbf{R}^{2}[-]$} \\
\cline { 2 - 7 } & CA & AM & CA & AM & CA & AM \\
\hline 21.09 & 13 & 13 & 15 & 18 & 0.94 & 0.97 \\
\hline 22.09 & 17 & 17 & 27 & 30 & 0.94 & 0.96 \\
\hline 23.09 & 19 & 18 & 27 & 27 & 0.92 & 0.94 \\
\hline 24.09 & 31 & 31 & 71 & 70 & 0.88 & 0.89 \\
\hline 25.09 & 27 & 29 & 50 & 49 & 0.85 & 0.87 \\
\hline 26.09 & 31 & 33 & 47 & 48 & 0.87 & 0.88 \\
\hline
\end{tabular}

All presented indicators are comparable for both analysed methods for calculating reflected solar radiation. Additionally in Figure 9 were presented coefficients of determination calculated for all analysed days in September. It can be noticed that for all days this coefficient is high. Moreover, coefficients of determination calculated for results obtained using authors method of calculation of reflected solar radiation is equal or higher than coefficients of determination calculated for results obtained using constant albedo model.

\section{Conclusions}

In paper was presented the new method of determination of reflected solar radiation in urban area using HDR image technique. Estimation of reflected solar radiation for two selected days characterised by sunny and cloudy sky conditions in September was performed. Determined reflected solar radiation show differences for extreme sky conditions: sunny and cloudy. Moreover, reflected solar radiation changes during day that is especially noticed for clear sky conditions. Obtained results were used to determine new model of reflected solar radiation considering its dependency from total horizontal solar radiation and sun altitude. Proposed model was implemented into ESP-r software. Finally, the validation of proposed model and model with constant albedo were conducted using measured value of solar radiation incident on western oriented façade. It was observed that results obtained from simulation using changeable reflected solar radiation have higher coefficient of determination than results obtained using constant value of ground reflectivity. Presented analysis confirms the importance of detailed modelling of reflected solar radiation on calculation results of the whole solar irradiance incident on vertical surface.

To conclude proposed method of reflected solar radiation evaluation based on photogrammetric techniques (HDR images) allow estimating the solar radiation reflected from the surrounding urban environment incident on the vertical surface of building envelope. Quantity of the reflected solar radiation incident on vertical surface is dependent on the characteristic of the surrounding environment and sky conditions. Proposed model of reflected solar radiation incident on vertical western oriented surfaces have a good correlation with measured data $\mathrm{R}^{2}>0.8$.

\section{Aknowledgments}

This work was funded in a framework of ERANet-LAC $2^{\text {nd }}$ Joint Call on Research and Innovation by NCBiR as part of the project entitled: Solar hybrid translucent component for thermal energy storage in buildings (acronym: SOLTREN).

\section{References}

Clarke J.A., (2001) Energy Simulation in Building Design, 2nd ed., Butterworth Heinemann, Oxford (UK).

Gueymard C., (1987) An Anisotropic Solar Irradiance Model for Tilted Surfaces and Its Comparison with Selected Engineering Algorithms, Solar Energy 385

Gong F.Y., Zeng Z.C., Zhang F, Li X., Ng E., Norford L.K., (2018) Mapping sky, tree, and building view 
factors of street canyons in a high-density urban environment, Building and Environment 134, 155167.

Inanici MN., (2006) Evaluation of high dynamic range photography as a luminance data acquisition system. Lighting Res. Technol. 38, 2 pp. 123-136

Ineichen, P., Perez, R., Seals R., (1987) The importance of correct albedo determination for adequately modeling energy received by tilted surfaces, Solar Energy 39 (4) 301-305.

Jacobs A. (2007) High Dynamic Range Imaging and its Application in Building Research. Advances in Building Energy Research, 1(1): 177-202.

Lam, J.C., Li, D.H.W., (1996) Correlation between global solar radiation and its direct and diffuse components. Building and Environment, 31, 527535.

Liu, B.Y.H., Jordan, R.C., (1960). The interrelationship and characteristic distribution of direct, diffuse, and total solar radiation. Solar Energy 4 (3), 1-19.
Liu, B.Y.H., Jordan, R.C., (1963) The long-term average performance of flat-plate solar energy collectors, Solar Energy 7, 53-74.

Moeck, M., Anaokar, S. (2006) Illuminance Analysis from High Dynamic Range Images. LEUKOS, The Journal of the Illuminating Engineering Society of North America 2:3, 211-228.

Nkemdirim, L., (1972) A note on the albedo of surfaces, Journal of Applied Meteorology 11, 867-874.

Perez, R., Ineichen, P., Seals, R., Michalsky, J., Stewart, R., (1990). Modeling daylight availability and irradiance components from direct and global irradiance. Solar Energy 44 (5), 271-289.

Thevenard, D., Haddad, K., (2006) Ground reflectivity in the context of building energy simulation, Energy and Buildings 38, 972-980.

Yoon K., Yun G., Jeon J., (2014) Kim K.S., Evaluation of hourly solar radiation on inclined surfaces at Seoul by Photographical Method. Solar Energy 100, 203216. 